\title{
O processo do design de interface para um gerenciador pessoal de tipos online
}

\author{
The process of the interface design for a personal online type manager
}

\author{
Mônica M. Koblinger e Vanessa Kupczik
}

Design de interface, tipografia, gerenciador de tipos online

\begin{abstract}
Este artigo relata a pesquisa que resultou no desenvolvimento de uma interface para web de um gerenciador pessoal de tipos. O projeto foi guiado com o propósito de utilizar o design como meio de alcançar melhorias relevantes no processo de escolha de tipografias para projetos que envolvam esta tarefa. Por meio de um referencial teórico que abrange a temática central e a temas relacionados a design de interface, junto a pesquisas com o público alvo, estabeleceu-se o problema que é caracterizado pela visualização precária e falta de organização dos tipos instalados em computadores pessoais, além de um tempo significativamente alto em que o profissional pode levar escolhendo tipos para seus projetos. A partir do levantamento de dados e definição do problema, adotou-se a metodologia dos cinco planos de Garrett para o desenvolvimento da interface com a intenção de planejar sua estrutura, focando nas necessidades dos usuários em todas as etapas. Ao fim, foi realizada a validação do projeto por meio de protótipo de alta fidelidade, comprovando a redução de tempo na escolha de fontes para um projeto.
\end{abstract}

Interface design, typography, online type manager

This article reports the research that resulted in the development of a web interface of a personal type manager. The project was guided with the purpose of using design as a means of achieving relevant improvements in the process of choosing typographies for projects involving this task. Through a theoretical reference that covers the central theme and themes related to interface design, along with research with the target public, the problem was established being characterized by the precarious visualization and lack of organization of the types installed in personal and professional computers, plus a significantly much time in which the professional can lead by choosing types for their projects. From the data collection and definition of the problem, the methodology of the five plans by Garrett was adopted for the development of the interface with the intention of planning its structure, focusing on the needs of the users in all the project stages. Finally, the project was validated by means of a high fidelity prototype, proving the time reduction in the choice of fonts for a project.

\section{Introdução}

Em uma realidade onde o profissional criativo precisa solucionar problemas criando materiais gráficos em uma rotina intensa e com prazos apertados, escolher a tipografia ou um conjunto certo delas para seus trabalhos pode ser um processo longo e complicado, uma vez que, geralmente, o profissional possui um leque extenso de tipos instalados em sua máquina e, em contrapartida, os softwares de criação à sua disposição apresentam muitas limitações. Algumas delas estão relacionadas a forma de exibição dos tipos que consiste em uma caixa seletora que as exibe em ordem alfabética de modo linear. Além disso, não é possível personalizar a visualização, organizar os tipos em categorias, nem tão pouco comparar de maneira rápida mais de uma tipografia.

Gavin Ambrose e Paul Harris (2011) expõem essa dinâmica e a importância da tipografia no design da seguinte maneira: "os diferentes papeis e funções dos tipos a que servem dentro de um projeto de design implicam um estudo cuidadoso por parte dos designers". Compreendendo este problema e também o design como responsável em desenvolver produtos interativos que fornecem suporte às atividades cotidianas das pessoas (PREECE, 2005), o projeto referente a este artigo teve como objetivo analisar as limitações do público alvo e desenvolver a interface de uma ferramenta que fosse capaz de suprir suas necessidades e melhorar suas experiências profissionais significativamente, baseado nas fundamentações da tipografia e princípios relacionados à ergonomia e usabilidade, design de interação e de interface.

Anais do 8 $\mathrm{CIDI}$ e 8은 CONGIC

Guilherme Santa Rosa; Cristina Portugal (orgs.)

Sociedade Brasileira de Design da Informação - SBDI

Natal | Brasil | 2017

ISBN 978-85-212-1305-5
Proceedings of the $8^{\text {th }} \mathrm{CIDI}$ and $8^{\text {th }}$ CONGIC

Guilherme Santa Rosa; Cristina Portugal (orgs.)

Sociedade Brasileira de Design da Informação - SBDI

Natal| Brazil | 2017

ISBN 978-85-212-1305-5 


\section{Fundamentos Aplicados}

É sabido que a tipografia exerce papel fundamental na comunicação e na propagação de informações. Para o desenvolvimento do projeto, foi adotada a definição sobre tipografia de Niemeyer (2006): "tipografia compreende o desenho e a produção de letras e sua adequada distribuição e espacejamento sobre uma superfície para transmitir informação e facilitar compreensão". Segundo a autora, a tipografia também exerce papel fundamental em questão de expressividade, cumprindo também objetivos estéticos e de usabilidade, atribuindo ao designer uma grande responsabilidade neste processo.

Assim que escolhida esta definição, foi preciso entender termos e conceitos básicos que pudessem orientar o planejamento de funções a serem implementadas na interface. De todos os conceitos estudados sobre a tipografia (dentre eles: estrutura dos tipos, métricas e formatos de fontes, por exemplo), os mais relevantes ao projeto referiam-se as famílias tipográficas e a classificação de tipos. Em relação às famílias tipográficas, adotou-se a definição de Niemeyer (2006) que as explica como "agrupamentos de caracteres que guardam as mesmas características essenciais de seu desenho, sendo subdivididas em categorias baseadas nos pesos de seus traços, largura relativa e inclinação". O surgimento de diversas famílias tipográficas tornou necessário desenvolver as classificações tipográficas afim de categorizar e agrupar famílias de tipos semelhantes.

Foram encontradas diversas classificações, das quais cada uma seguia uma justificativa e, apesar de algumas delas apresentarem semelhanças de famílias tipográficas, não havia um padrão a ser seguido. Entretanto, há uma classifiçção utilizada pela ATypl (Association Tipographique Internationale - Associação Internacional de Tipografia) que divide os tipos baseados na divisão desenvolvida por Maximilien Vox, recebendo o nome de Vox/ATypl. Essa classificação divide os tipos em:

- Romanos/Serifas;

- Sem Serifas;

- Semi Serifas;

- Manuais;

- Manuscritos;

- Góticos;

- Não Latinos.

Pohlen (2010) explica, no entanto, que quatro classificações foram criadas baseadas na Vox/ATypl, com o intuito de acrescentar categorias que agregassem famílias tipográficas criadas após a categorização de Vox. Segundo o autor, essas classificações recebiam as seguintes nomenclaturas: $V o x+1$, Vox +2 , $V o x+3$ e $V o x+4$, onde cada uma delas acrescentava uma certa quantidade de categorias de tipos, baseadas na necessidade encontrada no momento vigente. Para o projeto, foi utilizado a classificação Vox+2, pois ela acrescenta seis categorias atribuídas a tipos para telas. Porém, desta forma, a classificação adotada ficaria com treze categorias, o que, para o desenho da interface seria inviável. Sendo assim, com a intenção de otimizar o espaço que seria utilizado em tela, essas seis novas categorias formaram uma única, que foi nomeada de "display" (tradução do inglês para "tela").

A partir da compreensão dos dois conceitos apresentados acima, foi possível chegar a uma solução de exibição e organização dos tipos. A ferramenta não só exibia as fontes de uma forma mais evidente, como também a categorizava de acordo com a classificação Vox+2. A figura 1 demonstra como é feita a exibição padrão das fontes e a figura 2, mostra um corte ampliado das categorias de fontes escolhidas para o projeto. 


\section{CIDI 2017

Figura 1: tela de organização de fontes
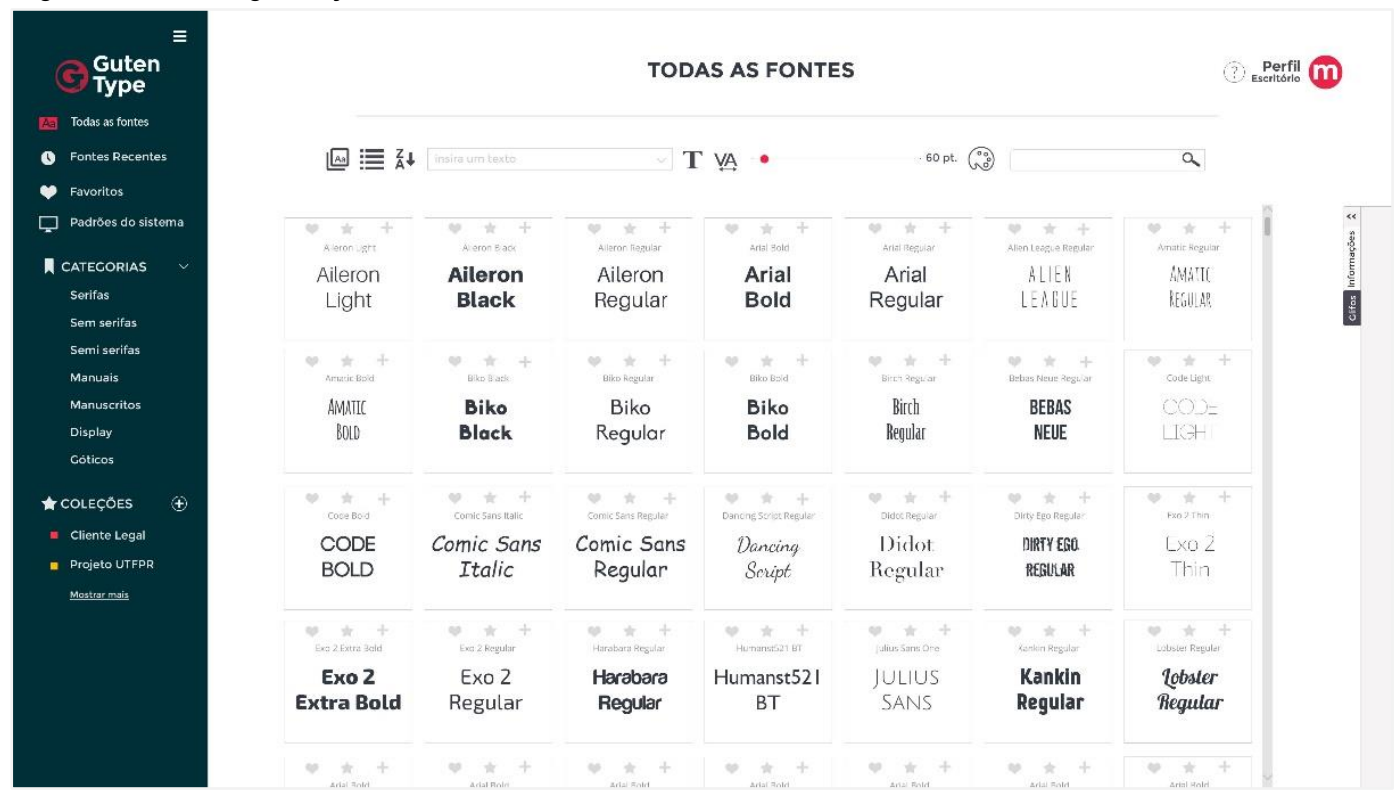

Figura 2: categorização de fontes, baseada na classificação Vox+2.
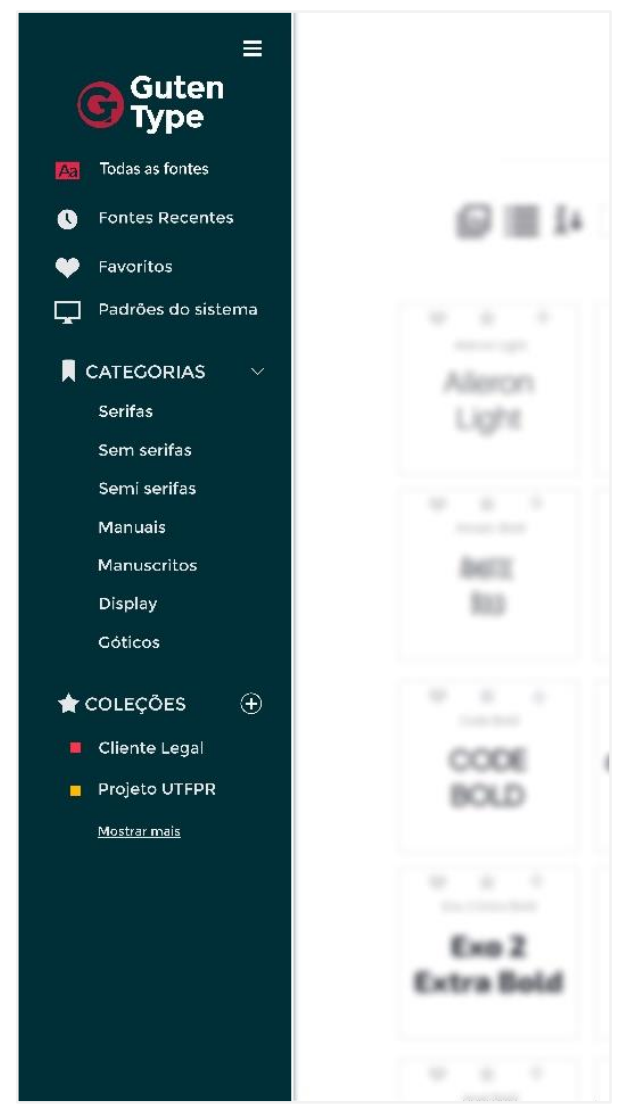

Enquanto os temas relacionados à tipografia eram estudados, uma pesquisa online foi realizada com o público-alvo na qual foi possível identificar os principais problemas enfrentados no processo de escolha de tipos. Parte dos usuários apontaram dificuldades na organização e categorização de tipos e, alguns deles, que tiveram alguma experiência com ferramentas similares, indicaram problemas estéticos e funcionais da interface do sistema utilizado, detalhes estes que são mais explorados no item 3 sobre pesquisas de campo do presente artigo. Preece (2005) afirma que é preciso refletir em como o design pode oferecer suporte para a realização de tarefas no desenvolvimento de uma interface, sendo preciso explorar e 
conhecer a realidade do usuário e tornar explícitas as suposições e crenças para criar um modelo conceitual que servirá de orientação para definir como o sistema deve se comportar, o que ele deve fazer e como deve se parecer. Contudo, para a definição do modelo conceitual, foi adotado o processo explicado por Brown (2009), que é dividido em dois momentos: o de divergência e o de convergência. No primeiro são coletadas informações e criadas diversas opções para que no segundo momento, as opções incoerentes sejam descartadas e seja possível fazer escolhas.

Definido o modelo conceitual do sistema, adotou-se o a noção de Preece (2005) para compreensão do design de interação. Segundo a autora, design de interação "significa criar experiências que melhorem e estendam a maneira como as pessoas trabalham, se comunicam e interagem", fato que está intrinsicamente relacionado ao que hoje é nomeado de UX Design, ou "User Experience Design" (design da experiência do usuário). Anderson (2003) explica que as grandes e verdadeiras experiências estão profundamente relacionadas às vivências e considerações mais profundas dos usuários, como motivações, emoções, desejos, culturas e crenças. Desta forma, a experiência do usuário é resultante de uma boa interação com a interface, cuja construção está diretamente associada a ergonomia e usabilidade.

Cybis et al. (2010) define a usabilidade como a "qualidade que caracteriza o uso de programas e aplicações" que depende de uma relação harmoniosa entre as características da interface e as do usuário. $O$ autor define a ergonomia, como a origem da usabilidade, uma vez que ela proporciona eficácia, eficiência e bem-estar ao usuário. Partindo-se destas definições, foram estudadas as heurísticas de usabilidade e princípios ergonômicos elaborados por Norman, Scapin e Bastien, Preece e Nielsen, conforme demonstrado a seguir:

Tabela 1: comparação entre as heurísticas de usabilidade

\begin{tabular}{|l|l|l|l|}
\hline Norman & Preece & Nielsen & Scapin e Bastien \\
\hline Beleza estética & Ser eficaz & $\begin{array}{l}\text { Visibilidade do estado do } \\
\text { sistema }\end{array}$ & Condução \\
\hline Confiabilidade & Ser eficiente & Mapeamento & Carga de trabalho \\
\hline Segurança & Ser seguro & $\begin{array}{l}\text { Liberdade e controle ao } \\
\text { usuário }\end{array}$ & Adaptabilidade \\
\hline Funcionalidade & Ser fácil de aprender & Prevenção de erros & Gestão de erros \\
\hline & & Reconhecimento & Consistência \\
\hline & & $\begin{array}{l}\text { Flexibilidade e eficiência } \\
\text { de uso }\end{array}$ & $\begin{array}{l}\text { Significação e } \\
\text { denominações }\end{array}$ \\
\hline & & $\begin{array}{l}\text { Design estético e } \\
\text { minimalista }\end{array}$ & Compatibilidade \\
\hline & & $\begin{array}{l}\text { Suporte para } \\
\text { reconhecimento }\end{array}$ & \\
\hline & & $\begin{array}{l}\text { Diagnóstico e } \\
\text { recuperação de erros }\end{array}$ & \\
\hline & & Ajuda e documentação & \\
\hline
\end{tabular}

O levantamento deste quadro comparativo permitiu uma visualização ampla dos princípios ergonômicos, sendo possível selecionar as características que se repetiam para criar um sistema de avaliação de usabilidade e ergonomia que foi utilizado como critério de verificação para a análise de similares e como suporte para o desenvolvimento da interface do gerenciador de tipos online. Desta forma, o sistema abrangia os itens: 


\section{CIDI2017 ${ }^{g^{\mathrm{h}} \mid 1 \mathrm{ID}}$

- Estética;

- Segurança e prevenção de erros;

- Feedback imediato;

- Eficiência;

- Consistência.

Alguns exemplos das heurísticas aplicadas na interface são expostos nas figuras 3 e 4, que mostram a dinâmica de seleção de fontes, exemplificando feedback imediato, segurança e prevenção de erros. Na figura 3, o feedback imediato acontece no momento da seleção de fontes, quando a interface exibe um contorno de cor diferenciada para as fontes selecionadas, junto a um pop-up na parte inferior direita que informa a quantidade escolhida pelo usuário. A figura 4 mostra a abertura do pop-up que exibe as fontes selecionadas e permite a exclusão das que não são mais pertinentes, ilustrando a prevenção de erros. As outras heurísticas foram aplicadas em outras funções da interface.

Figura 3: feedback imediato na seleção de fontes para comparação ou combinação
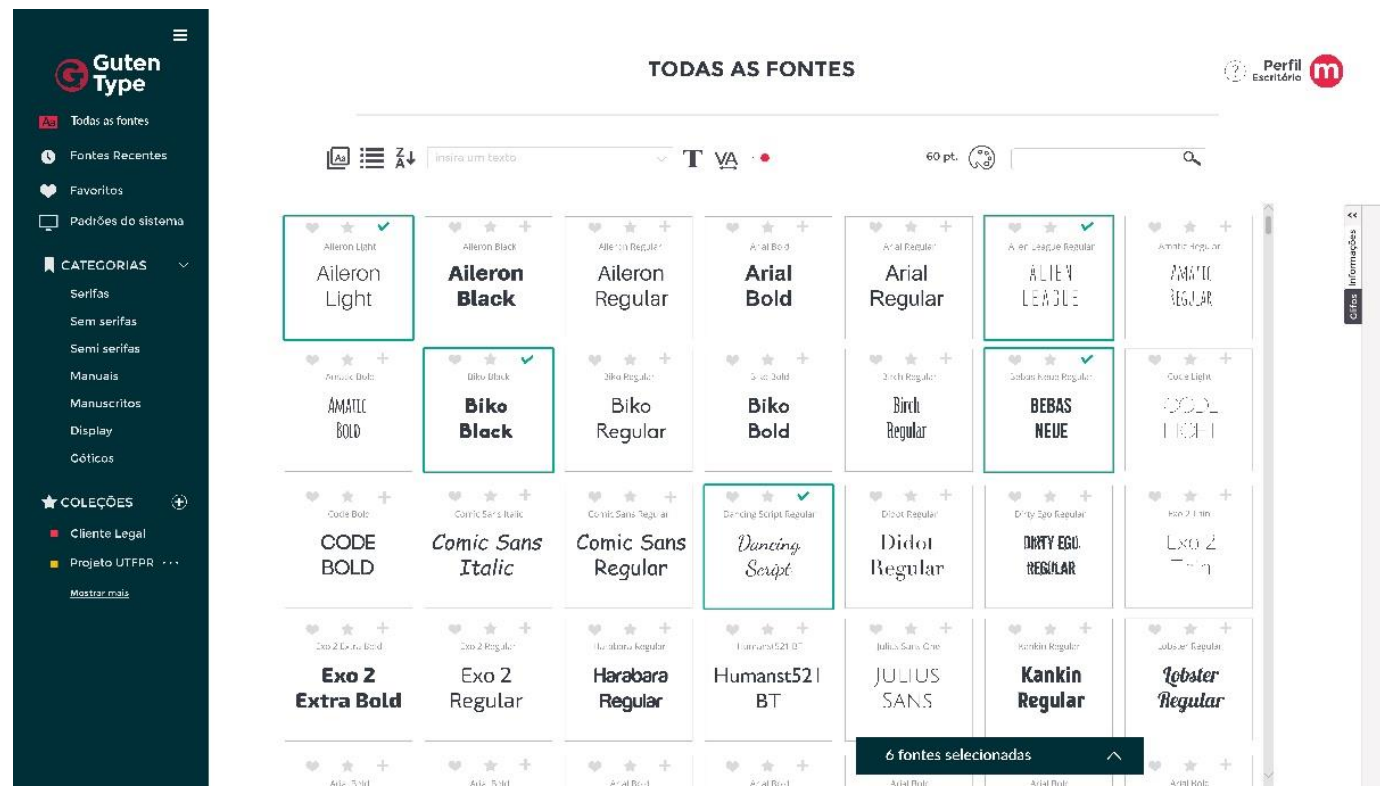

Figura 4: permissão de desfazer a seleção de fontes exemplificando previsão de erros da interface

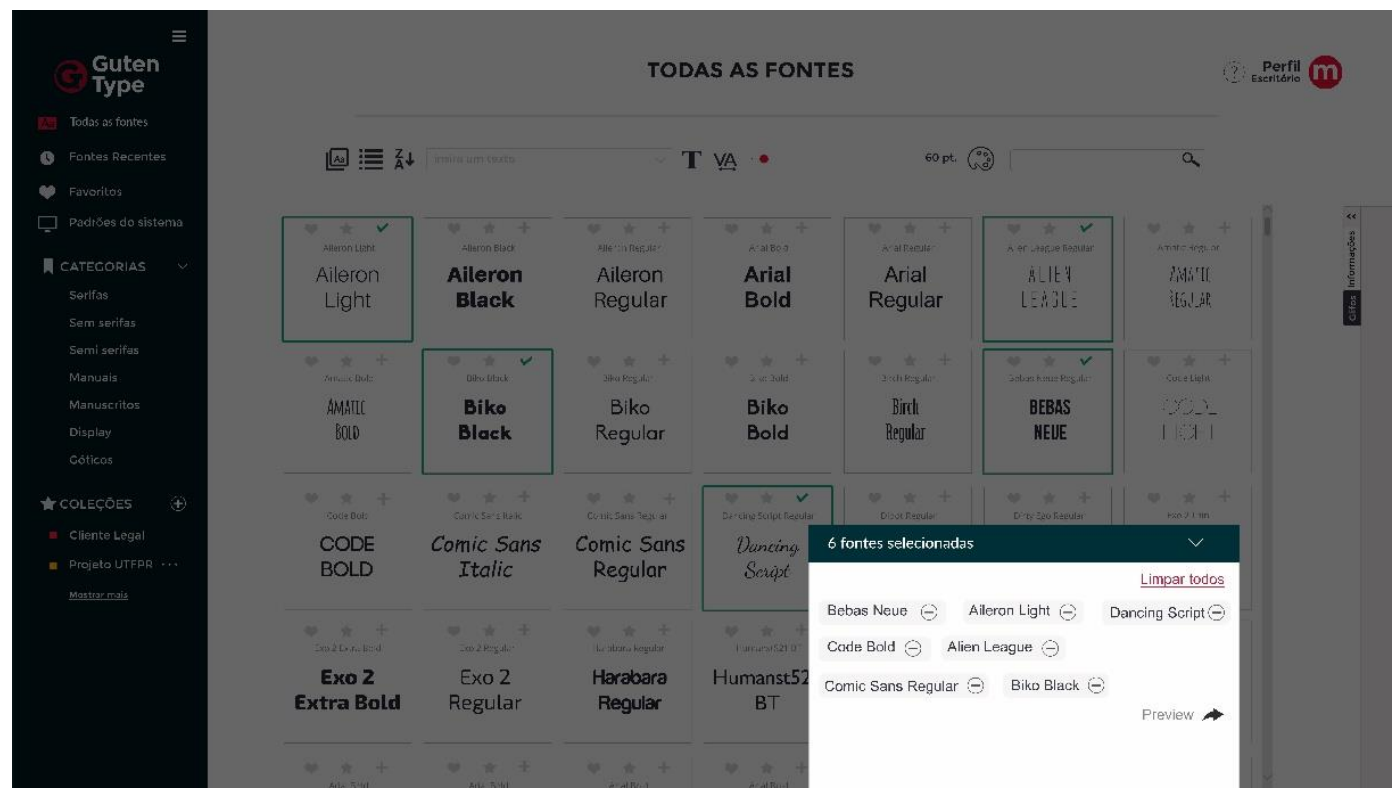


O último tema que apoiou o desenvolvimento do projeto foi relacionado ao design de interfaces. Garrett (2011) explica que o desenvolvimento de uma interface é baseado em intenções conscientes e explícitas. Baseado nesta compreensão, o desenvolvimento da interface do projeto se apoiou no conceito dos cinco planos, também idealizado por Garrett, que são utilizados na estruturação de uma interface e permitem conhecer a experiência do usuário, os problemas que envolvem o projeto e as possíveis ferramentas para resolvê-los. Os cinco planos são definidos em:

- Estratégia: compreensão das necessidades do usuário e definição de objetivos;

- Escopo: especificações funcionais e de conteúdo;

- Estrutura: mapa da interação entre as páginas;

- Esqueleto: definição dos elementos da interface;

- Superfície: desenvolvimento gráfico da interface.

Segundo o autor, as decisões tomadas em cada plano afetam as decisões que são tomadas nos planos seguintes e, para que haja um equilíbrio entre as tarefas que o usuário deve cumprir e qual informação a interface oferece a ele, os cinco planos devem ser pensados com fluidez, ou seja, quase que simultaneamente.

Além da utilização do método de Garrett, foi necessário compreender quais são os elementos empregados na construção de uma interface. Estes elementos são construídos com base em convenções utilizadas pelo usuário de modo que o sistema tenha uma boa compreensão e siga as heurísticas de usabilidade. Os elementos estudados foram:

- Nomes;

- Cores;

- Tipografia;

- Iconografia;

- Layout

- Grid.

A definição dos elementos para o projeto foi baseada também na explicação do comportamento do usuário segundo Krug (2005). Em seu livro, o autor afirma que os usuários não se esforçam muito para utilizar algo que parece difícil. Segundo ele, uma página deve ser evidente, autoexplicativa e intuitiva o suficiente para que o usuário consiga atingir o seu objetivo, ainda que nem tudo que esteja na página possa ser visível. Sendo assim, a aparência dos elementos, suas definições e nomeações e sua organização na página devem criar um reconhecimento simples de suas respectivas funções.

\section{Pesquisas de Campo}

Além dos estudos e compreensão dos fundamentos de design que envolvem o planejamento e construção de um projeto de interface, foram realizadas pesquisas com os usuários para compreender quais suas necessidades e também, uma análise de ferramentas similares para identificar possíveis problemas a serem descartados, melhorados ou ideias a serem mantidas.

A primeira pesquisa com os usuários tinha caráter exploratório, com questões quantitativas e qualitativas e foi realizada online. Seu principal objetivo era validar a proposta do projeto, descobrindo qual era seu potencial e compreender as dificuldades que os usuários tinham ao trabalhar com tipografia no dia-a-dia. Após sete dias de divulgação, o questionário obteve sessenta respostas.

Os resultados desta primeira pesquisa mostraram que o maior público do projeto era designer (dentre as opções que abrangiam também publicidade, marketing, estudantes e outras profissões), com $63 \%$ das respostas. Do total de participantes, $87 \%$ afirmou baixar muitas fontes em suas máquinas e $13 \%$ não. $82 \%$ estima ter mais de 100 fontes instaladas em suas máquinas, destes, $58 \%$ estima ter entre 101 e 500 fontes, $20 \%$ entre 501 e 1000 e $10 \%$ possuem acima de 1000 fontes. Em relação ao tempo de escolha de tipos, $35 \%$ dos participantes afirmam gastar mais de 30 minutos, $27 \%$ leva de 21 a 30 minutos, $25 \%$ leva de 11 
a 20 minutos e apenas $13 \%$ leva de 5 a 10 minutos. Quanto a organização de fontes, apenas $18 \%$ dos usuários gerenciam suas fontes, porém, $80 \%$ do total de usuários não conhece ou utiliza algum gerenciador de tipos. Por fim, $92 \%$ dos participantes declaram interesse pelo projeto.

Dentre os problemas mais relatados entre os usuários que conheciam algum gerenciador de tipos, os mais citados foram:

- Dificuldade em organizar ou categorizar os tipos;

- Interface pouco intuitiva e layout desagradável;

- Navegação confusa e falta de fluidez;

- Softwares instaláveis que faziam a máquina ficar mais lenta ou travar.

Os pontos positivos de softwares utilizados pelos usuários eram, em alguns casos, a possibilidade de categorizar os tipos e a personalização de sua exibição.

Com base nas indicações dos participantes da pesquisa e também no conhecimento prévio de alguns programas e sites que possuía uma proposta semelhante à do projeto, foi realizada a análise de similares. O método da análise, conforme citado anteriormente no item 2 deste artigo, foi baseado nos itens do sistema de avaliação de usabilidade e ergonomia e também na ponderação em relação as características dos elementos de cada interface. Os sistemas avaliados foram: Myfontbook, Wordmarkit, Flipping Typical, Nexus Font e Corel Font Manager, sendo os três primeiros sistemas online e os dois últimos softwares instaláveis.

Ao final da análise, foi elaborada uma tabela que exibia uma pontuação de um a quatro para cada uma das características avaliadas, onde um era ruim e quatro muito bom. Com ela foi possível visualizar de modo geral quais características eram mais fragilizadas e, de modo específico, quais programas possuíam características positivas que poderiam ser mantidas na nova proposta. A tabela com os resultados é exibida abaixo:

Tabela 2: resultado da análise de similares

\begin{tabular}{|l|l|l|l|l|l|}
\hline & MyFontbook & Wordmarkit & F. Typical & Nexus Font & $\begin{array}{l}\text { Corel F. } \\
\text { Manager }\end{array}$ \\
\hline Interface & 03 & 02 & 02 & 03 & 03 \\
\hline Estética & 01 & 03 & 02 & 02 & 04 \\
\hline Feedback & 02 & 02 & 02 & 02 & 04 \\
\hline Segurança & 03 & 01 & 01 & 03 & 04 \\
\hline Eficiência & 02 & 02 & 03 & 02 & 04 \\
\hline Consistência & 02 & 03 & 02 & 02 & 04 \\
\hline Funções & 03 & 02 & 01 & 04 & 04 \\
\hline
\end{tabular}




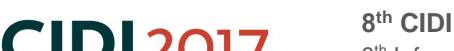

As primeiras pesquisas e análises feitas foram fundamentais como pontos de partida para a construção da interface. Uma vez concluídas, foram desenvolvidos os primeiros wireframes e então os primeiros protótipos digitais, que foram utilizados para o primeiro teste de usabilidade.

O primeiro teste de usabilidade foi feito online e contou com a participação de cinco usuários. Foram designadas algumas tarefas para cada participante e no final eles poderiam fazer comentários sobre a experiência, de modo a orientar os ajustes que deveriam ser feitos. A compreensão dos usuários neste momento foi, de modo geral, positiva, porém, foram necessárias diversas modificações.

O segundo teste de usabilidade foi realizado após a conclusão das alterações indicadas no primeiro teste. Concomitante a este o segundo teste, foi apresentada a identidade visual do projeto. Neste momento, o projeto já possuía maior consistência e estava mais próximo do real planejado. Este teste também foi realizado online, mas contou com 25 usuários. Além das tarefas designadas, o teste também mensurou o tempo que cada participante levou para realiza-las e possibilitou que fossem expostas suas opiniões em relação a suas experiências. Desta forma, foi possível validar a proposta de tornar a experiência com tipografia relativamente mais rápida e de compreender se ainda haveriam ajustes a serem realizados.

\section{Resultados}

A busca pela boa tipografia é incessante e depende de inúmeros fatores para que seja bem selecionada. Compreender a sua importância e a dinâmica necessária para sua escolha foi fundamental para definir quais ferramentas poderiam ser incluídas no projeto de interface.

Em paralelo, compreender as vantagens de uma boa usabilidade e as possibilidades de interação que o mundo virtual permite, motivou a busca por soluções que envolvessem o maior dinamismo possível em todas as ferramentas oferecidas.

No final do projeto, o gerenciador de tipos online permitia a organização dos tipos instalados no computador pessoal, oferecia a possibilidade de comparar dois ou mais tipos (figura 5), combinar tipografias entre si (figura 6), categorizar os tipos em coleções de acordo com os projetos ao qual o usuário estivesse envolvido, permitia a troca de inspirações tipográficas entre os usuários (figura 7) e ainda sugeriu a possibilidade de acessar a lista de tipografias existentes em outros computadores acessados pelo usuário.

Figura 5: tela de comparação de tipos

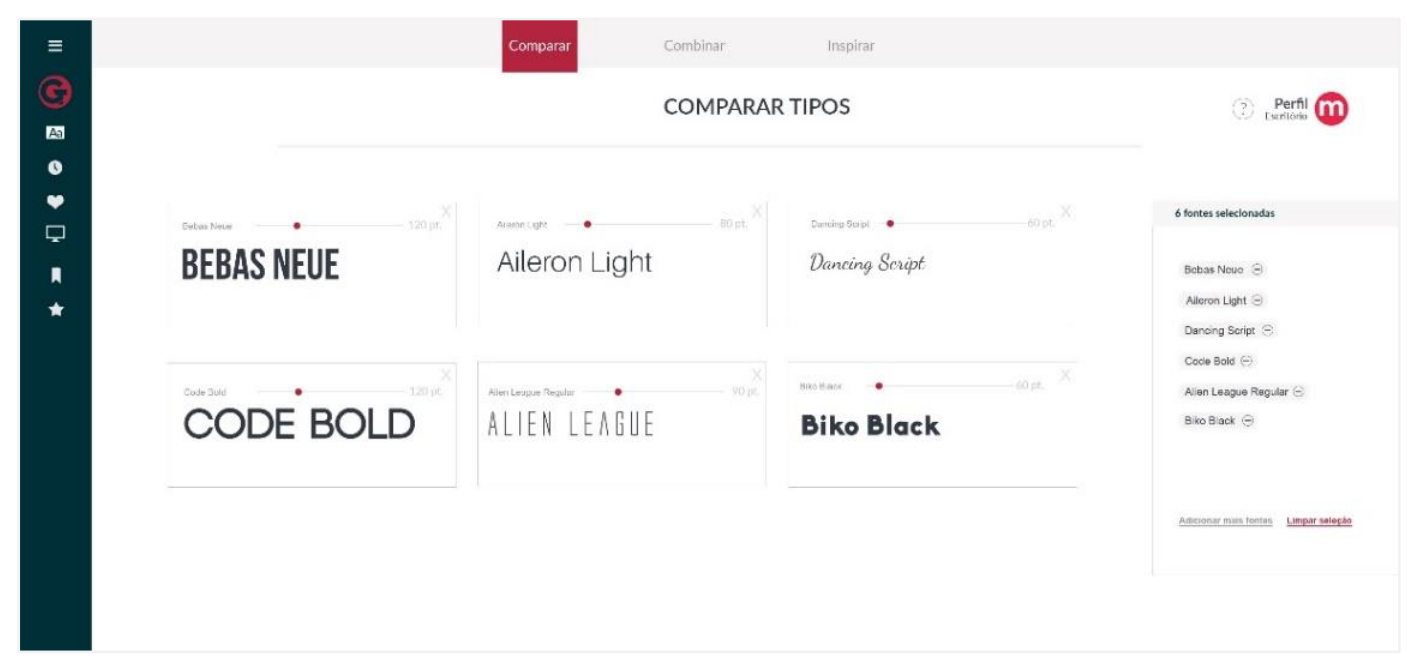




\section{CIDI 2017 seln \\ $8^{\text {th }}$ CONGIC \\ mesign

Figura 6: tela de combinação de fontes
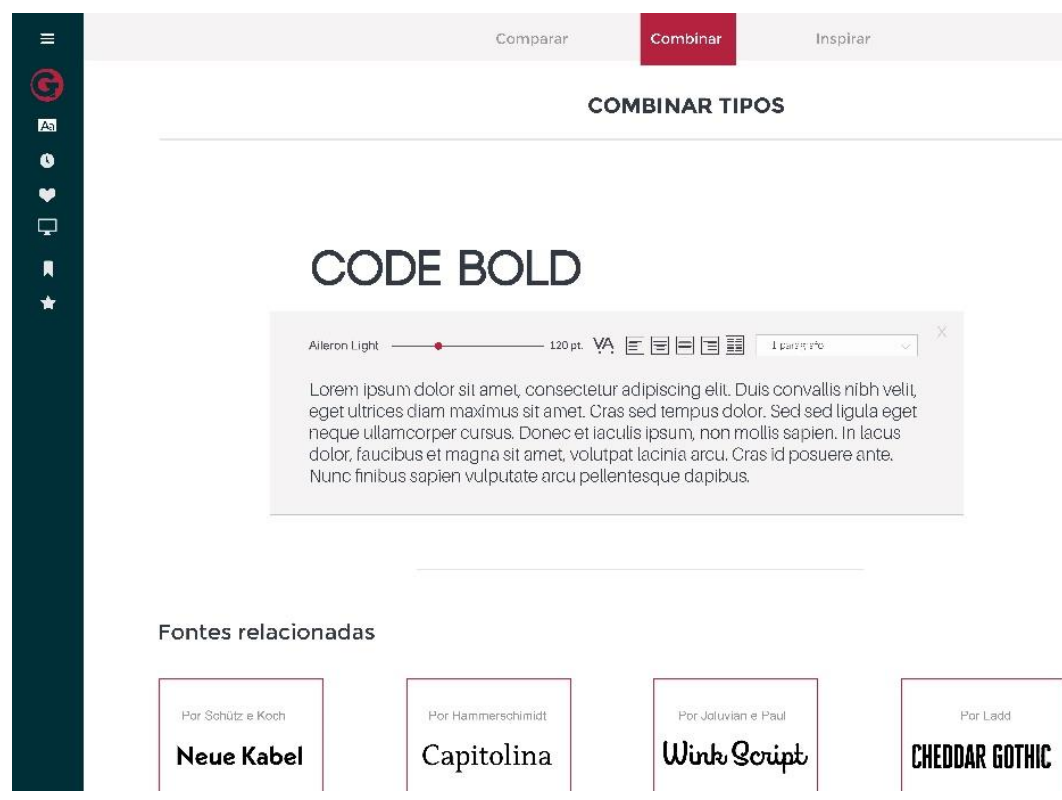

Figura 7: tela de busca por inspirações tipográficas

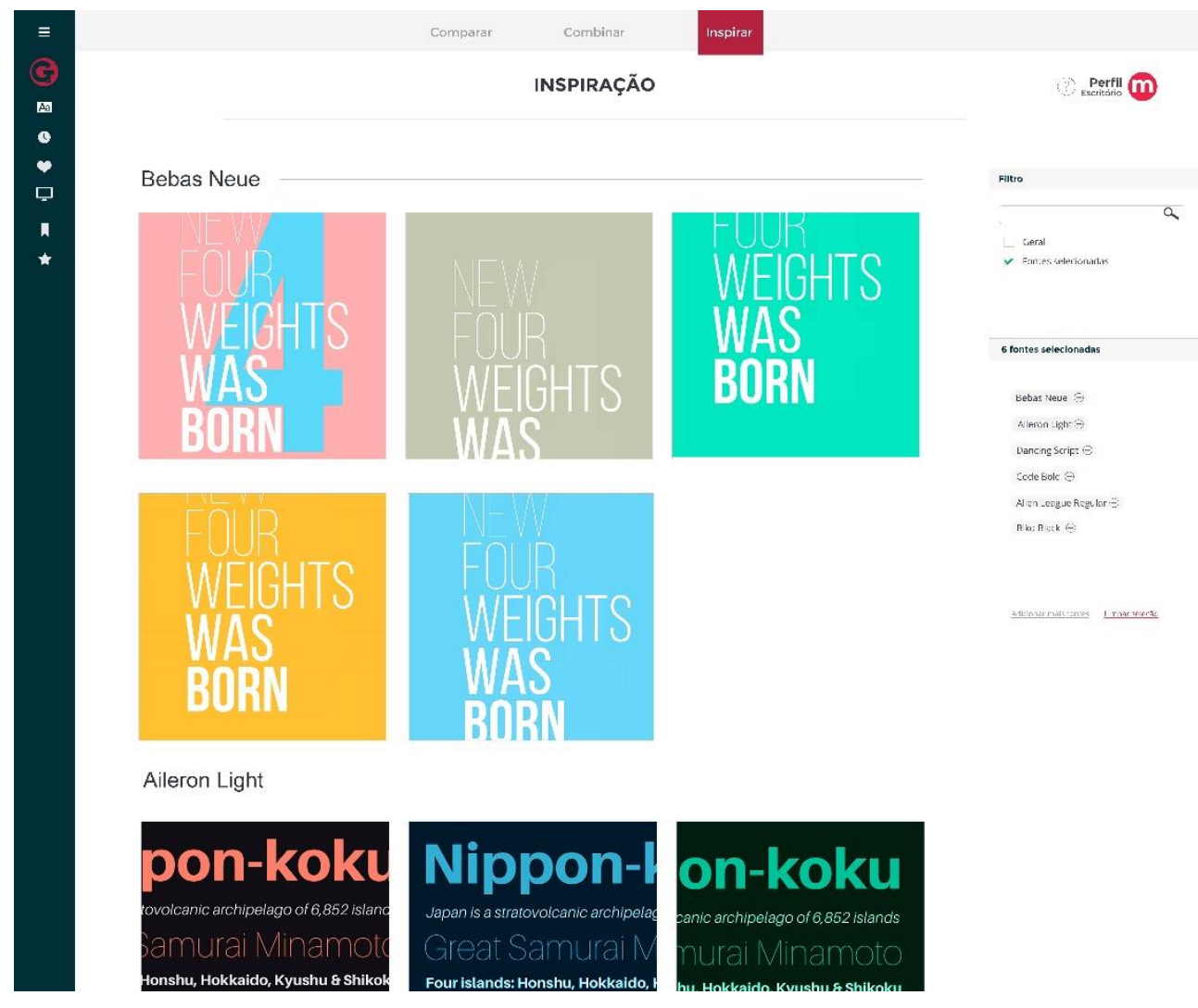

\section{Conclusão}

Embora ao fim do segundo teste de usabilidade, algumas modificações tenham sido sugeridas, foi possível concluir que unindo os fundamentos de tipografia, design de interação e usabilidade, além da utilização do método de Garrett, foi possível criar um protótipo viável para uso comercial que foi construído em um processo onde os usuários foram envolvidos em 
diferentes fases do projeto, surtindo grande importância para que a interface se tornasse um projeto exequível. Além disso, o projeto alcançou o objetivo proposto de facilitar a organização e seleção de fontes e prevê uma redução no tempo de escolha significativa para os usuários.

Como análise teórica, a carga de conhecimento adquirida com o projeto permitiu a compreensão da importância do planejamento e estudos prévios para que projetos de interface, principalmente as de média e grande complexidade, possam ser os mais assertivos possíveis e atendam, de fato, as necessidades do usuário final mantendo o caráter criativo e inovador de cada um.

\section{Referências}

AMBROSE, Gavin; HARRIS, Paul. Design thinking. Porto Alegre: Bookman, 2011

ANDERSON, Stephen P. The Fundamentals of Experience Design. Poet Painter, 2009.

Disponível em:<http://www.poetpainter.com/thoughts/category/Experience-Design-

Strategy/>. Acesso em: 12/09/2016

BROWN, Tim. Design thinking: uma metodologia poderosa para decretar o fim das velhas ideias. Rio de Janeiro, RJ: Campus: Elsevier, 2010.

CYBIS, Walter; BETIOL, Adriana Holtz; FAUST, Richard. Ergonomia e usabilidade: conhecimentos, métodos e aplicações. 2. ed. São Paulo (SP): Novatec, 2010

GARRETT, Jesse James. The elements of user experience: User-centered design for the web and beyond. 2. ed. United States: New Riders, 2011.

KRUG, Steve; FERNANDES, Acauan Pereira. Não me faça pensar: uma abordagem de bom senso à usabilidade na web. 2. ed. Rio de Janeiro: Alta Books, 2006

NIEMEYER, Lucy. Tipografa: uma apresentação. 4. ed. Rio de Janeiro, RJ: 2AB, 2010

POHLEN, Joep, Letter Fountain. Alemanha, Taschen, 2010

PREECE, Jennifer; ROGERS, Yvonne; SHARP, Helen. Design de interação: além da interação homem-computador. Porto Alegre: Bookman, 2005.

Mônica M. Koblinger, Universidade Tecnológica Federal do Paraná, Brasil. monii.ka@hotmail.com

Vanessa Kupczik, Universidade Federal do Paraná, Brasil.vanessakupczik@gmail.com 